\title{
Ontogeny influences developmental physiology of post-transplant Quercus rubra seedlings more than genotype
}

\author{
Joshua L. Sloan ${ }^{1,2} \cdot$ Douglass F. Jacobs ${ }^{1}$
}

Received: 22 June 2016 / Accepted: 8 September 2016 / Published online: 3 October 2016

(C) INRA and Springer-Verlag France 2016

\begin{abstract}
- Key message Seedling ontogeny exerted a greater influence on physiological activity of Quercus rubra seedlings than genetics; thus, it may be more important to use an appropriate growth index to account for seedling ontogeny in experiments than to control for genetic variation.

- Context Members of the genus Quercus exhibit semideterminate growth, resulting in complex and developmentally variable endogenous physiological patterns. The Quercus morphological index (QMI; Hanson et al. Tree Physiol. 2:273$281,1986)$ was developed as a tool to relate physiological patterns to morphologically identifiable ontological stages, thereby allowing for treatment or measurement of seedlings at uniform ontological stages rather than strictly by chronology.

- Aims Although clear physiological patterns relative to seedling ontogeny have been observed using the QMI in pretransplant half-sibling seedlings, we sought to determine whether physiological patterns remain consistent across genotypes within a species.

- Methods We examined net photosynthesis, transpiration, leaf chlorophyll concentrations, and chlorophyll fluorescence
\end{abstract}

Handling Editor: Erwin Dreyer

Contribution of the co-authors JLS designed and conducted the experiment, analyzed the data, and co-wrote the manuscript.

DFJ supervised the work and co-wrote the manuscript.

Douglass F. Jacobs

djacobs@purdue.edu

1 Hardwood Tree Improvement and Regeneration Center, Department of Forestry and Natural Resources, Purdue University, West Lafayette, IN, USA

2 Present address: John T. Harrington Forestry Research Center, New Mexico State University, P.O. Box 359, Mora, NM 87732, USA
$\left(F_{v} / F_{m}\right)$ throughout the first flush after transplant for northern red oak (Quercus rubra L.) seedlings from three half-sibling families.

- Results Neither net photosynthesis nor transpiration rates varied by family, whereas leaf chlorophyll concentrations and $F_{v} / F_{m}$ differed significantly. Despite family differences for magnitudes of some parameters, no interactions between QMI growth stage and family were observed, and patterns of all parameters relative to growth stage were consistent across families. Net photosynthetic rates, transpiration rates, and $F_{v} /$ $F_{m}$ increased during the flush, while leaf chlorophyll concentration decreased, suggesting that chlorophyll synthesis is not a limiting factor during leaf maturation in this species.

- Conclusion Findings indicate that QMI-based physiological patterns may be at least regionally applicable within a given Quercus species.

Keywords Growth index $\cdot$ Episodic growth $\cdot$ Plant development $\cdot$ Seedling physiology $\cdot$ Experimental error

\section{Introduction}

Species in the genus Quercus exhibit semi-determinate growth patterns, frequently characterized by recurrent flushes within a growing season resulting in complex endogenous physiological patterns relative to many co-occurring species with determinate or indeterminate growth patterns (Hanson et al. 1986; Dickson et al. 2000a, b). The Quercus morphological index (QMI) was developed by Hanson et al. (1986) as a growth index for physiological studies in this genus and has been used to identify ontological, rather than chronological, periods of seedling development. Thus, the QMI makes it possible to perform experimental treatments or measurements at particular ontological stages and states of physiological 
activity, thereby reducing experimental error resulting from the use of seedlings of various developmental stages in physiology studies (Hanson et al. 1986; Dickson et al. 2000a, b). The use of the QMI in seedling physiology studies and, consequently, the validity of findings from these studies depend on the assumption that all Quercus seedlings of a given species and ontological stage exhibit similar physiological patterns; however, this assumption has not previously been explicitly examined.

The existence and importance of intraspecific variation is acknowledged by such practices as common garden studies and the establishment of seed zones, and high levels of intraspecific variation have been found for both European and North American oak species (Kleinschmit 1993; Kriebel 1993). However, detailed studies to characterize the extent and nature of endogenous physiological variability within a species in relation to specific ontological events, especially studies investigating members of the genus Quercus, are relatively few. The questions to be answered in this regard are twofold. First, does physiological activity in relation to discrete morphologically identified indicators of seedling ontogeny vary appreciably among family groups within a species and, if so, to what extent? Second, if substantial variability among family groups occurs at comparable growth stages, to what extent does it result from similar patterns of physiological activity throughout the species (differing primarily in the magnitude of activity) as opposed to the presence of multiple, inherently different patterns of endogenous physiological activity? Such questions of variation must be understood to make informed inferences as to whether results of any given isolated research experiment (often involving individuals that are relatively homogeneous genetically) are likely to apply to a species as a whole. Issues of intraspecific variation influence the applicability of research findings; for example, the vast majority of temperate deciduous hardwood seedlings produced for outplanting in the eastern USA, including most northern red oak seedlings, originate from genetically unimproved materials (Jacobs and Davis 2005), implying high degrees of intraspecific variation and poor predictability of seedling performance.

Many instances of intraspecific variation (both morphological and physiological) are regional in nature, often linked to environmental conditions, such as changing precipitation or temperature regimes throughout the range of a species. In cork oak (Quercus suber L.), a common garden study using acorns collected from throughout the species range found variation in leaf size, specific leaf area, and carbon isotope discrimination corresponding to rainfall and temperature differences between the seed sources (Ramírez-Valiente et al. 2010). Another common garden study examining intraspecific variation in white ash (Fraxinus americana L.) involving representatives from populations throughout the native range also linked variability in survival, diameter growth, leaf mass and nitrogen per unit area, and carbon isotope discrimination to differences in precipitation between geographic points of origin; however, the same study found no evidence of significant variation in lightsaturated photosynthesis or stomatal conductance between populations (Marchin et al. 2008). Similarly, in red spruce (Picea rubens Sarg.) and black spruce (Picea mariana (Mill.) B.S.P.), regional intraspecific variation was observed in such parameters as germination time, hypocotyl height, epicotyl height, and total cotyledon area (Major et al. 2003).

In other instances, intraspecific variation occurs within a relatively small and homogenous geographical area, does not seem to result from adaptation to any obvious environmental factors, and appears to be a reflection of inherently diverse physiological patterns within a species. A study of intra- and interspecific genetic variability within and among several populations of white oak (Quercus alba L.), swamp white oak (Quercus bicolor Willd.), and bur oak (Quercus macrocarpa Michx.) in northeastern Illinois, USA, found not only the expected interspecific variability but also highly significant intraspecific genetic differentiation within each species examined; intraspecific variation was comparable to observed levels of interspecific variability (Craft and Ashley 2006). However, analysis of variation in chloroplast DNA of northern red oak (Quercus rubra L.) populations in Indiana, USA, found that individuals of different geographic populations varied more than individuals within populations (RomeroSeverson et al. 2003).

Studies of intraspecific variation within European species of the genus Quercus have revealed similar variability. A study of monoterpene emissions of holm oak (Quercus ilex L.) found that the species contains no fewer than three distinct chemotypes, each with a characteristic monoterpene emission profile; although magnitude of these emissions varied seasonally, composition of the emissions was found to be inherently, consistently, and qualitatively different among chemotypes within the species (Staudt et al. 2001). Additionally, a study of the responses of sessile oak (Quercus petraea (Mattuschka) Liebl.) and English oak (Quercus robur L.) to flooding, using seedlings grown from acorns collected from a limited geographical area within a single forest, found substantial variability both between and within species, as well as the occurrence of individuals exhibiting extreme phenotypes for parameters such as density of induced hypertrophied lenticels, adventitious root number, and adventitious root biomass (Parelle et al. 2007).

The literature suggests that levels of intraspecific variation can differ substantially between species within a given genus and, consequently, should be assessed for each species, as experimental needs require. Studies employing the QMI assume the relation of physiological patterns relative to morphologically identified ontological stages remains consistent within a given species, although this assumption is rarely overtly examined or discussed and remains questionable for most 
members of the genus. This study was initiated to determine whether northern red oak seedlings of different openpollinated half-sibling groups exhibit similar post-transplant physiological patterns with regard to QMI growth stages and whether findings of studies of northern red oak employing the QMI can be expected to apply regionally within the species. To this end, regional intraspecific variation exhibited in patterns of gas exchange, chlorophyll fluorescence, and leaf chlorophyll concentrations during the first flush of growth following transplanting were evaluated.

\section{Materials and methods}

\subsection{Plant material and transplant}

Seedlings were grown from acorns collected in fall 2005 from three open-pollinated northern red oak mother trees representative of two populations within the state of Indiana (designated families 47, 49, and 97) located in a seed orchard at the Indiana Department of Natural Resources nursery near Vallonia, Indiana, USA ( $\left.38^{\circ} 48^{\prime} \mathrm{N}, 86^{\circ} 06^{\prime} \mathrm{W}\right)$. This seed orchard contains mother trees established from scion wood collected from dominant northern red oak trees from around the state, with families 47 and 49 originating from Carroll County, Indiana, and family 97 originating from Allen County, Indiana. Acorns collected from the mother trees representative of these families in the seed orchard were sown in beds at the nursery and grown according to standard nursery production methods (Jacobs 2003) during the 2006 growing season; the dormant seedlings were operationally lifted in late fall and stored at $3{ }^{\circ} \mathrm{C}$ until April 2007.

In April of 2007, 24 seedlings from each half-sibling group were removed from cold storage for transplanting. Each seedling of each half-sibling group was randomly assigned a QMI growth stage (defined below) for physiological measurements and harvest, planted in 6.231 pots (TPOT2, Stuewe \& Sons, Inc.; Tangent, OR, USA) containing a 1:1 ( $v: v)$ mixture of sand and sphagnum peat, watered to container capacity (determined gravimetrically at time of transplant), and placed on benches in a climate-controlled greenhouse in the Department of Horticulture and Landscape Architecture greenhouse facility at Purdue University in West Lafayette, IN, USA $\left(40^{\circ} 25^{\prime}\right.$ $\mathrm{N}, 86^{\circ} 55^{\prime} \mathrm{W}$ ) under ambient light and day length with day/ night temperatures of $24 / 20^{\circ} \mathrm{C}$. Seedlings were watered to container capacity daily throughout the study period, and greenhouse conditions were chosen so as to provide nonlimiting growth conditions favorable to this species.

\subsection{Regular morphological measurements}

Quercus morphological index growth stages for physiological measurements and harvest were identified by a series of regular morphological measurements as described by Hanson et al. (1986). The linear shoot growth stage (SL) was indicated by cessation of elongation of the first new internode of the flush, the linear leaf growth stage (LL) by cessation of elongation of the shoot as a whole, and the lag stage (LAG) by cessation of elongation of the second leaf from the top of the new flush.

\subsection{Physiological measurements}

Physiological measurements were conducted on each seedling at its assigned growth stage. Measurements included net photosynthesis, transpiration, leaf chlorophyll concentration, and the ratio of variable fluorescence to maximal fluorescence in a dark-acclimated leaf $\left(F_{v} / F_{m}\right)$. All measurements were performed on the same leaf.

Net photosynthesis was measured on mid-flush, sunexposed leaves from 16:00 to 17:00 using an LI-6400 portable photosynthesis system equipped with a 6400 02B LED light source on a $2 \times 3 \mathrm{~cm}$ broadleaf sampling head (Licor; Lincoln, NE, USA). Its settings were as follows: block temperature $=25{ }^{\circ} \mathrm{C}$, photosynthetically active radiation $(\mathrm{PAR})=350 \mu \mathrm{mol} \mathrm{m} \mathrm{m}^{-2}$, reference $\mathrm{CO}_{2}=400 \mu \mathrm{mol} \mathrm{mol}{ }^{-1}$, and flow rate $=400 \mathrm{mmol} \mathrm{s}^{-1}$. At 23:30, $F_{v} / F_{m}$ measurements were performed using an LI-6400 equipped with a 6400-40 leaf chamber fluorometer (Licor; Lincoln, NE, USA); measurement at this time ensured that seedlings experienced a minimum of $2 \mathrm{~h}$ of darkness to facilitate dark-acclimation of the leaves prior to measurement. Machine settings were the same as above, with light source and leaf chamber fluorometer settings adjusted as recommended in the user manual for $F_{v} / F_{m}$ measurements.

Following chlorophyll fluorescence measurements, the leaf was removed, 10 leaf punches $(8 \mathrm{~mm}$ diameter) were taken, chlorophyll extractions were immediately performed, and chlorophyll $a$ and $b$ concentrations were quantified spectrophotometrically (Arnon 1949; Hiscox and Israelstam 1979).

\subsection{Statistical analyses}

Data were analyzed as a completely randomized $3 \times 3$ factorial design $(n=8$ seedlings for each family $\times$ growth stage combination with one leaf measured per seedling) using analysis of variance $(P<0.05)$ followed by Tukey's multiple pairwise comparison $(\alpha=0.05)$ to identify significant differences between families and growth stages. All analyses were performed using SAS software version 9.4 (SAS Institute, Inc., Cary, NC, USA). 


\section{Results}

\subsection{Photosynthesis}

No interaction occurred between family and growth stage for net photosynthesis $(P=0.28)$. No difference in rates of net photosynthesis was observed between families over the course of the experiment $(P=0.12)$. Growth stage affected rates of net photosynthesis $(P<0.01)$, with higher rates of net photosynthesis occurring at LAG stage than at either the SL or LL stages (Fig. 1).

\subsection{Transpiration}

No interaction occurred between family and growth stage for transpiration $(P=0.57)$. No difference in transpiration rates was observed between families over the course of the experiment $(P=0.11)$. Growth stage, however, did have an effect $(P=0.01)$, with higher transpiration rates during LAG stage relative to the SL growth stage (Fig. 2).

\subsection{Chlorophyll concentration}

No interaction between family and growth stage was observed for chlorophyll $a$ concentration $(P=0.48)$. A family effect was observed $(P=0.01)$, with family 47 exhibiting a higher chlorophyll $a$ concentration $(0.0067 \pm 0.0017 \mathrm{mg}$ chlorophyll $a$ per $100 \mathrm{mg}$ fresh mass) relative to family $49(0.0056 \pm 0.0016 \mathrm{mg}$ chlorophyll $a$ per $100 \mathrm{mg}$ fresh mass). Additionally, a growthstage effect was observed $(P<0.01)$, with LAG stage having a lower chlorophyll $a$ concentration $(0.0044 \pm 0.0009 \mathrm{mg}$ chlorophyll $a$ per $100 \mathrm{mg}$ fresh mass) relative to the SL or LL growth stages $(0.0073 \pm 0.0012 \mathrm{mg}$ chlorophyll $a$ per $100 \mathrm{mg}$ fresh mass and $0.0066 \pm 0.0012 \mathrm{mg}$ chlorophyll $a$ per $100 \mathrm{mg}$ fresh mass, respectively).

With regard to chlorophyll $b$ concentration, no interaction between family and growth stage was observed $(P=0.56)$, and no family effect was observed $(P=0.17)$. However, a growth-stage effect was observed $(P<0.01)$, with LAG stage having a lower chlorophyll $b$ concentration $(0.0118 \pm 0.0024 \mathrm{mg}$ chlorophyll $b$ per $100 \mathrm{mg}$ fresh mass $)$ relative to the SL or LL growth stages $(0.0176 \pm 0.0028 \mathrm{mg}$ chlorophyll $b$ per $100 \mathrm{mg}$ fresh mass and $0.0165 \pm 0.0025 \mathrm{mg}$ chlorophyll $b$ per $100 \mathrm{mg}$ fresh mass, respectively).

For total chlorophyll concentration, no interaction between family and growth stage was observed $(P=0.54)$, and no family effect was observed $(P=0.07)$. However, a growthstage effect was observed $(P<0.01)$, with LAG stage having a lower total chlorophyll concentration $(0.0162 \pm 0.0033 \mathrm{mg}$ total chlorophyll per $100 \mathrm{mg}$ fresh mass) relative to the SL or LL growth stages $(0.0250 \pm 0.0039 \mathrm{mg}$ total chlorophyll per $100 \mathrm{mg}$ fresh mass and $0.0231 \pm 0.0034 \mathrm{mg}$ total chlorophyll per $100 \mathrm{mg}$ fresh mass, respectively; Fig. 3).

\subsection{Chlorophyll fluorescence}

No interaction occurred between family and growth stage with regard to $F_{v} / F_{m}(P=0.38)$. A family effect was observed $(P<0.01)$, with family 47 having a reduced $F_{v} / F_{m}$ value relative to families 49 and 97 . Additionally, a growth-stage
Fig. 1 Net photosynthesis by growth stage. Values displayed are means $( \pm$ standard error of the mean), where $n=24$ for each growth stage. Growth stages are shoot linear $(S L)$, leaf linear $(L L)$, and lag $(L A G)$; stages marked with the same letter did not differ significantly $(\alpha=0.05)$
Net photosynthesis by growth stage

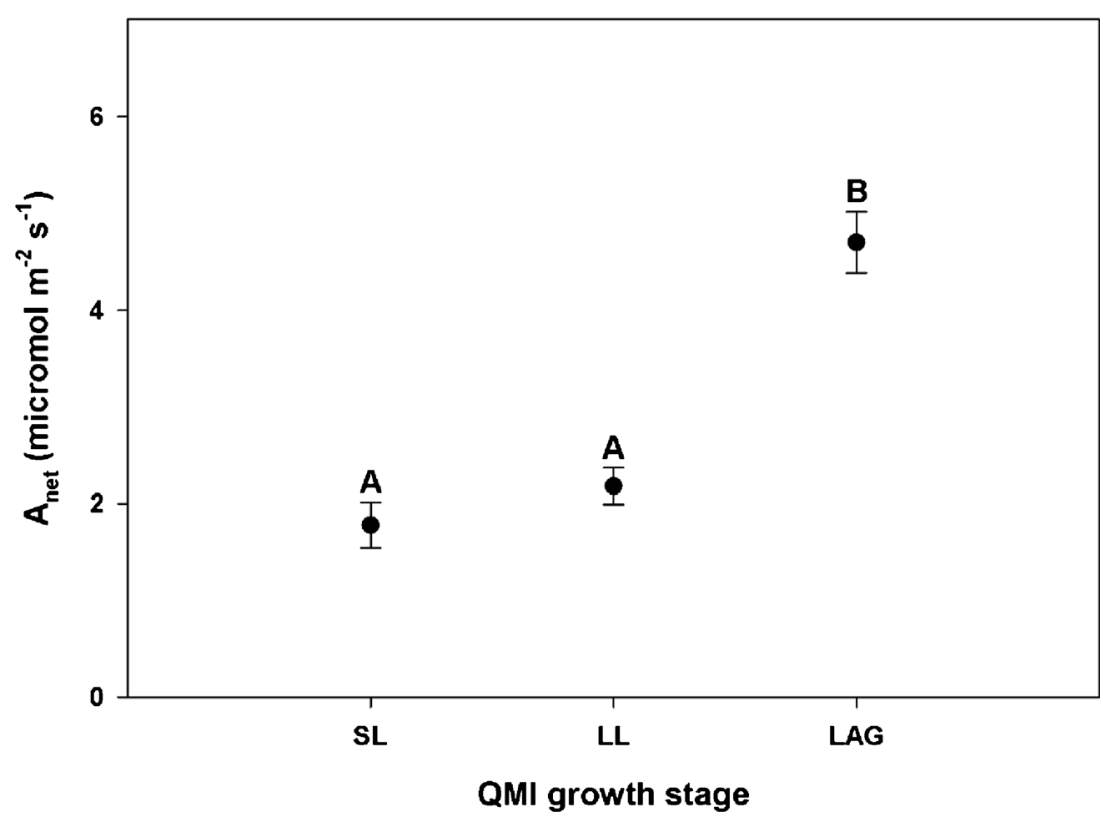


Fig. 2 Transpiration rate by growth stage. Values displayed are means ( \pm standard error of the mean), where $n=24$ for each growth stage. Growth stages are shoot linear $(S L)$, leaf linear $(L L)$, and lag $(L A G)$; stages marked with the same letter did not differ significantly $(\alpha=0.05)$

\section{Transpiration rate by growth stage}

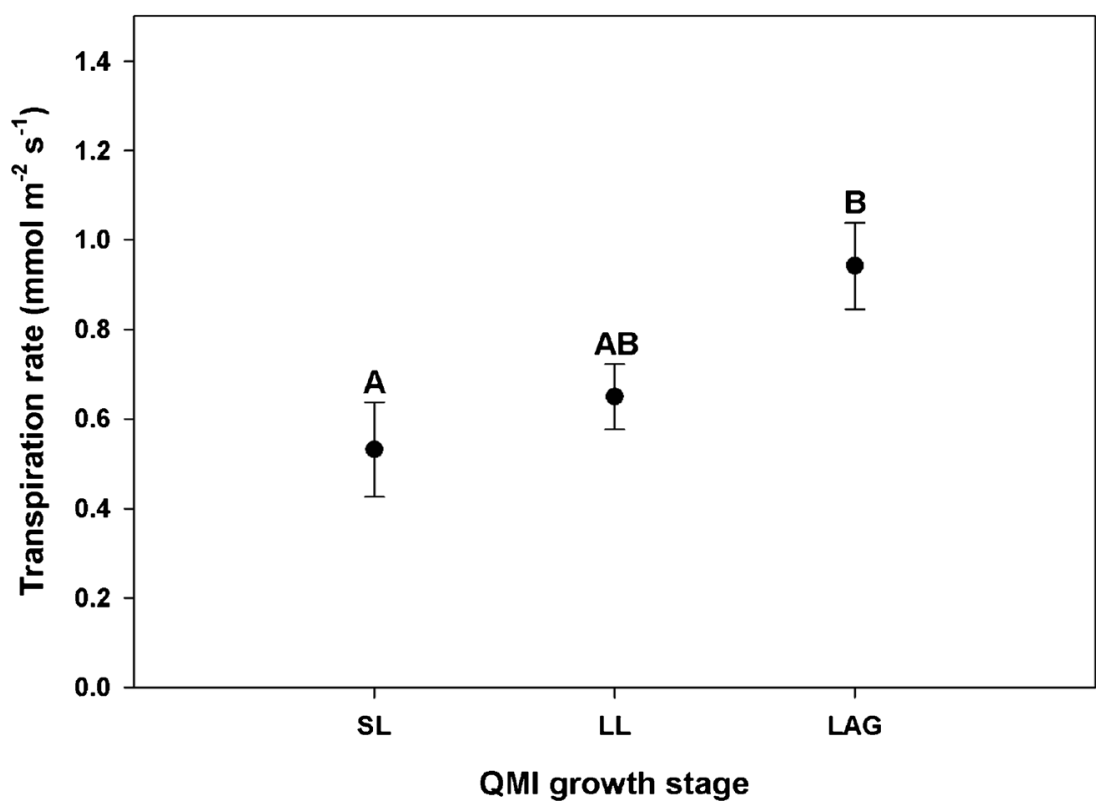

effect was observed $(P=0.01)$, with LAG stage having a higher $F_{v} / F_{m}$ value relative to the SL growth stage (Fig. 4).

\section{Discussion}

Minimal intraspecific variation was observed among the three half-sibling groups of northern red oak used in the experiment, and in no case did the underlying ontological patterns exhibited by net photosynthetic rate, transpiration rate, leaf total chlorophyll concentration, or chlorophyll fluorescence appear to vary by family group. The apparent absence of intraspecific variation in patterns of physiological activity relative to growth stage is supported by the lack of interaction between the growth stage and family group factors for all measured parameters. The low variability among family groups in the present study contrasts with high levels of intraspecific variation observed in studies with other Quercus species (Staudt et al. 2001; Craft and Ashley 2006; Ramírez-
Fig. 3 Leaf chlorophyll concentration by growth stage. Values displayed are means $( \pm$ standard error of the mean), where $n=24$ for each growth stage. Growth stages are shoot linear $(S L)$, leaf linear $(L L)$, and lag $(L A G)$; stages marked with the same letter did not differ significantly $(\alpha=0.05)$

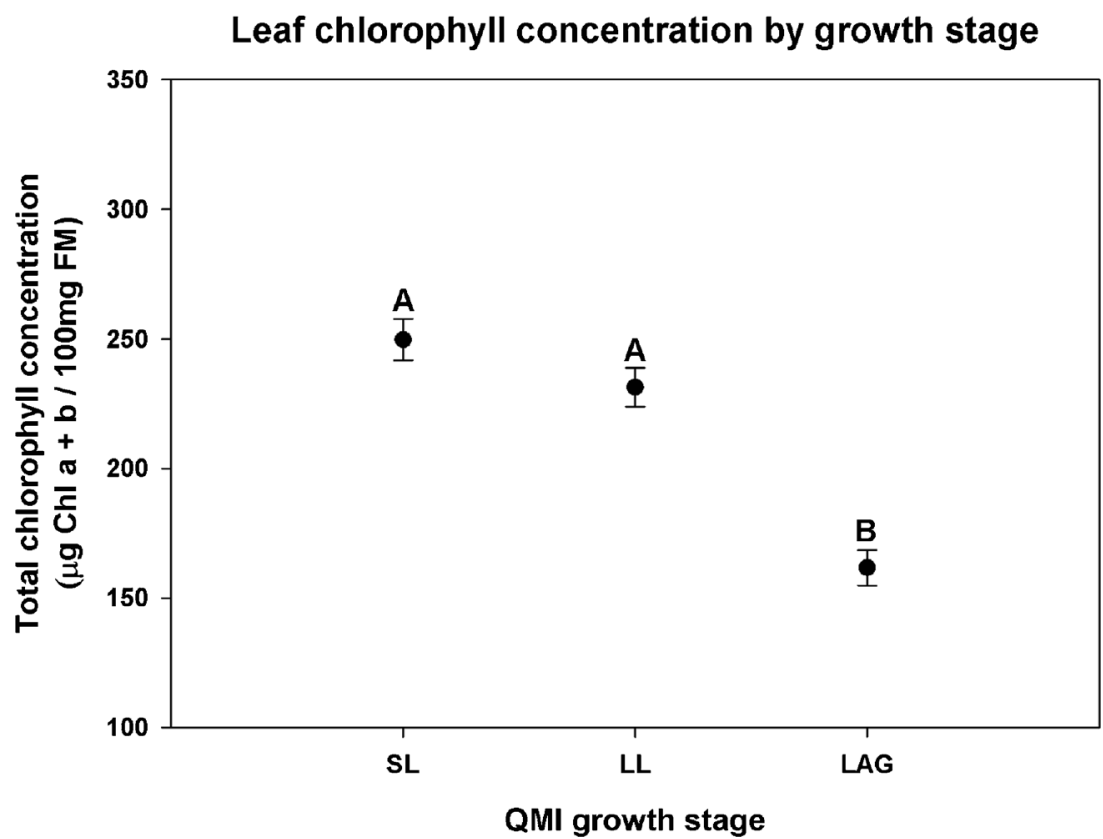


Fig. 4 Chlorophyll fluorescence by growth stage. Values displayed are means $( \pm$ standard error of the mean), where $n=24$ for each growth stage. Growth stages are shoot linear $(S L)$, leaf linear $(L L)$, and lag $(L A G)$; stages marked with the same letter did not differ significantly $(\alpha=0.05)$
Chlorophyll fluorescence by growth stage

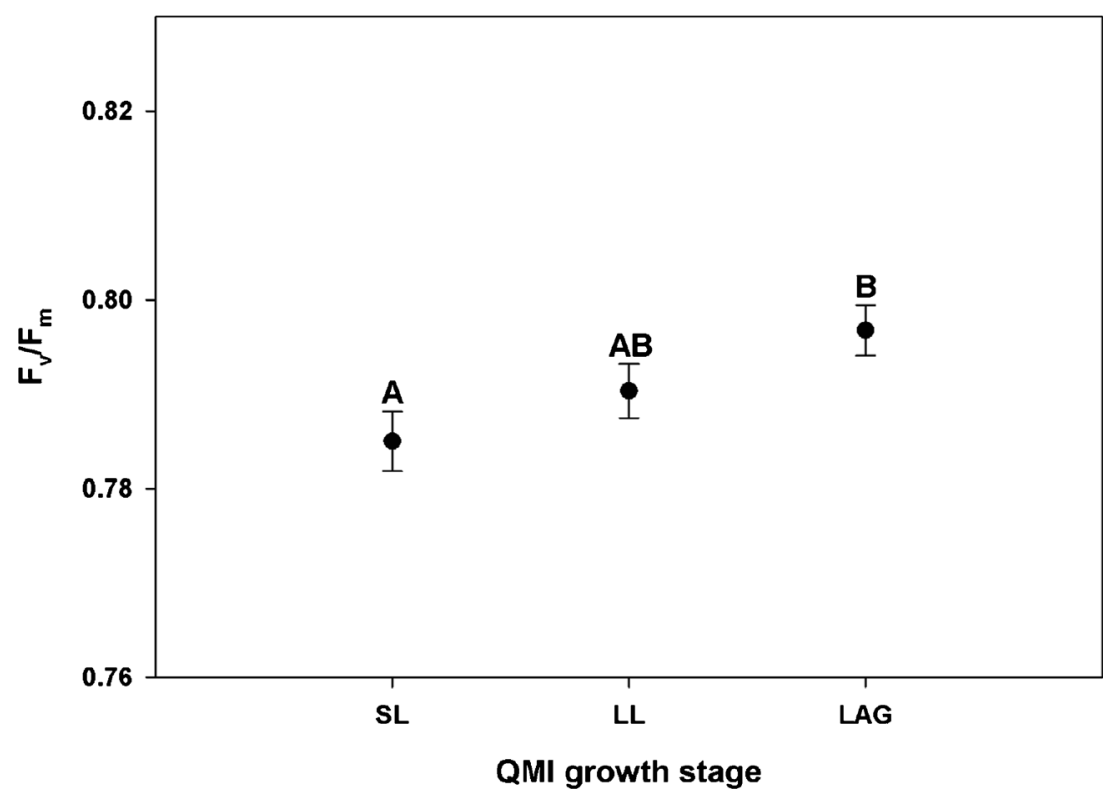

Valiente et al. 2010); however, it should be noted that all three families used originated from within Indiana, USA, and therefore may not be fully representative of variation within this species across its range. Growth stage exerted much greater influence on the magnitudes and patterns of physiological activity in post-transplant seedlings than family group, further highlighting the importance of using a growth index in physiological research of Quercus spp. In principle, the findings of this study also support the potential for broad applicability within any species of research findings based upon a morphological index appropriate to that species.

Somewhat surprisingly, neither net photosynthetic rates nor transpiration rates varied by family; however, growth stage had a large effect on both net photosynthesis and transpiration (Figs. 1 and 2, respectively), with both parameters increasing steadily throughout the flush until LAG stage when the experiment was concluded. Isebrands et al. (1994) observed patterns of steadily increasing net photosynthetic rates during leaf expansion and development in pre-transplant northern red oak seedlings during the course of the first flush of growth following germination and again in second-flush leaves; the present study finds these patterns to occur similarly in post-transplant seedlings, remaining consistent across the family groups examined.

Chlorophyll $a$, chlorophyll $b$, and total chlorophyll concentration responses to growth stage were very similar across families, suggesting that patterns of chlorophyll synthesis occur with ontological consistency across genotypes for northern red oak seedlings. Growth stage heavily influenced these same parameters, with steep declines in mass-based concentrations of each observed at LAG stage (Fig. 3). Such a pattern is suggestive of the growth dilution of chlorophyll during leaf expansion over the course of the flush, and, considering the relatively low levels of current photosynthate partitioned into pigments following the completion of leaf expansion observed by Dickson et al. (2000b), the present data suggest that chlorophyll synthesis is largely completed by the SL growth stage of the flush. Additionally, the observed inverse relation between net photosynthetic rates and leaf chlorophyll concentrations suggests that increases in carbon exchange rates of new leaves, which continue to increase after full leaf expansion (Isebrands et al. 1994), result from the maturation of nonchlorophyll leaf constituents.

Family was found to affect $F_{v} / F_{m}$, an index reflecting the maximal potential efficiency of PSII, with family 47 having a reduced efficiency relative to families 49 and 97 ; however, patterns of $F_{v} / F_{m}$ response to growth stage remained highly consistent across families. As with other measured physiological patterns, $F_{v} / F_{m}$ also responded to growth stage, increasing as the flush progressed to LAG stage, where it reached the highest levels observed in this experiment (Fig. 4).

As was observed for gas exchange parameters, maximal potential efficiency of PSII increased throughout the flush concurrently with the steady decrease in mass-based chlorophyll concentration, providing further indication that chlorophyll synthesis is not a limiting factor with regard to photochemical maturation and photosynthetic efficiency during leaf development of post-transplant northern red oak seedlings. Maxwell and Johnson (2000) attribute alterations in efficiency of non-photochemical quenching as the primary cause of changes in $F_{v} / F_{m}$, implying that observed increases in PSII efficiency during and after leaf expansion may result from the continued synthesis of accessory pigments associated with non-photochemical quenching. $F_{v} / F_{m}$ has historically been 
employed in stress studies of various Quercus species to observe the effects of treatment-induced oxidative stress on PSII, and members of the genus Quercus have typically been found capable of maintaining high $F_{v} / F_{m}$ values under a variety of adverse conditions (Epron and Dreyer 1992, 1993; Rossini et al. 2006; Sloan et al. 2016). However, inasmuch as the present study demonstrates that endogenous patterns of ontological development can influence patterns of chlorophyll fluorescence, stress studies employing chlorophyll fluorescence measurements should take note of potential confounding effects resulting from interactions between endogenous patterns of seedling development and exogenous stress stimuli.

\section{Conclusion}

Net photosynthesis, transpiration rate, chlorophyll concentration, and chlorophyll fluorescence depend heavily upon ontological growth stage in post-transplant northern red oak seedlings. Additionally, chlorophyll fluorescence and chlorophyll $a$ content were found to vary by family. However, despite variation between families with regard to the values of measured parameters, physiological patterns across growth stages were similar and consistent among half-sibling families. Based on these findings, we conclude that the QMI assumption of consistent physiological patterns across growth stages within a species is likely at least regionally valid with regard to northern red oak. This evidence suggests that use of an appropriate growth index may lead to greater reductions in sources of experimental error than the use of genetically homogeneous plant material.

Acknowledgments We would like to thank Jim McKenna and Lisa Worthen Alexander for generously supplying the seedlings used in this experiment, as well as Bradley Hart and Amy Densborn for the technical assistance they contributed to this project.

\section{Compliance with ethical standards}

Funding This research was financially supported by the Fred M. van Eck Forest Foundation for Purdue University.

\section{References}

Arnon DI (1949) Copper enzymes in isolated chloroplasts. Polyphenoloxidase in Beta vulgaris. Plant Physiol 24:1-15

Craft KJ, Ashley MV (2006) Population differentiation among three species of white oak in northeastern Illinois. Can J For Res 36:206-215

Dickson RE, Tomlinson PT, Isebrands JG (2000a) Allocation of current photosynthate and changes in tissue dry weight within northern red oak seedlings: individual leaf and flush carbon contribution during episodic growth. Can J For Res 30:1296-1307

Dickson RE, Tomlinson PT, Isebrands JG (2000b) Partitioning of current photosynthate to different chemical fractions in leaves, stems, and roots of northern red oak seedlings during episodic growth. Can J For Res 30:1308-1317

Epron D, Dreyer E (1992) Effects of severe dehydration on leaf photosynthesis in Quercus petraea (Matt.) Liebl.: photosystem II efficiency, photochemical and nonphotochemical fluorescence quenching and electrolyte leakage. Tree Physiol 10:273-284

Epron D, Dreyer E (1993) Photosynthesis of oak leaves under water stress: maintenance of high photochemical efficiency of photosystem II and occurrence of non-uniform $\mathrm{CO}_{2}$ assimilation. Tree Physiol 13:107-117

Hanson PJ, Dickson RE, Isebrands JG, Crow TR, Dixon RK (1986) A morphological index of Quercus seedling ontogeny for use in studies of physiology and growth. Tree Physiol 2:273-281

Hiscox JD, Israelstam GF (1979) A method for the extraction of chlorophyll from leaf tissue without maceration. Can J Bot 57:1332-1334

Isebrands JG, Tomlinson PT, Dickson RE (1994) Carbon fixation and allocation in northern red oak. In: Biology and silviculture of northern red oak in the north central region: a synopsis. Eds. J.G. Isebrands and R.E. Dickson. USDA For. Serv., Gen. Tech. Rep. NC-173, pp. 21-31

Jacobs DF (2003) Nursery production of hardwood seedlings. Purdue University Department of Forestry and Natural Resources, Hardwood Tree Improvement and Regeneration Center, FNR-212. $8 \mathrm{pp}$

Jacobs DF, Davis AS (2005) Genetic consideration in the operational production of hardwood nursery stock in the eastern United States. Native Plants J 6:4-13

Kleinschmit J (1993) Intraspecific variation of growth and adaptive traits in European oak species. Ann For Sci 50(Suppl. 1):166s-185s

Kriebel HB (1993) Intraspecific variation of growth and adaptive traits in North American oak species. Ann For Sci 50(Suppl. 1):153s-165s

Major JE, Mosseler A, Barsi DC, Campbell M, Rajora OP (2003) Morphometric, allometric, and developmentally adaptive traits in red spruce and black spruce. I. Species and seed-source variation. Can J For Res 33:885-896

Marchin RM, Sage EL, Ward JK (2008) Population-level variation of Fraxinus americana (white ash) is influenced by precipitation differences across the native range. Tree Physiol 28:151-159

Maxwell K, Johnson GN (2000) Chlorophyll fluorescence-a practical guide. J Exp Bot 51:659-668

Parelle J, Brendel O, Jolivet Y, Dreyer E (2007) Intra- and interspecific diversity in the response to waterlogging of two co-occurring white oak species (Quercus robur and Q. petraea). Tree Physiol 27:10271034

Ramírez-Valiente JA, Sánchez-Gómez D, Aranda I, Valladares F (2010) Phenotypic plasticity and local adaptation in leaf ecophysiological traits of 13 contrasting cork oak populations under different water availabilities. Tree Physiol 30:618-627

Romero-Severson J, Aldrich P, Feng Y, Sun W, Michler C (2003) Chloroplast DNA variation of northern red oak (Quercus rubra L.) in Indiana. New Forest 26:43-49

Rossini M, Panigada C, Meroni M, Colombo R (2006) Assessment of oak forest condition based on leaf biochemical variables and chlorophyll fluorescence. Tree Physiol 26:1487-1496

Sloan JL, Islam MA, Jacobs DF (2016) Reduced translocation of current photosynthate precedes changes in gas exchange for Quercus rubra seedlings under flooding stress. Tree Physiol 36:54-62

Staudt M, Mandl N, Joffre R, Rambal S (2001) Intraspecific variability of monoterpene composition emitted by Quercus ilex leaves. Can J For Res 31:174-180 